\title{
Effect of Agrobacterium co-cultivation stage on explant response for subsequent genetic transformation in Soybean (Glycine max (L.) Merr.)
}

\author{
Phetole Mangena
}

Department of Biodiversity, School of Molecular and Life Sciences, Faculty of Science and Agriculture, University of Limpopo, Private Bag X1106, Sovenga, 0727, Republic of South Africa

*Email: phetole.mangena@ul.ac.za

\section{ARTICLE HISTORY}

Received: 02 July 2021

Accepted: 25 August 2021

Available online: 30 September 2021

\section{KEYWORDS}

Agrobacterium tumefaciens

Cotyledonary nodes

Genetic transformation

In vitro culture

Glycine max

\section{ABSTRACT}

The establishment of an efficient in vitro genetic transformation protocol in soybean depends upon an effective interaction between the explants and Agrobacterium tumefaciens. Therefore, a study was conducted at the University of Limpopo, South Africa, between September 2019 and May 2020 to evaluate explant amenability and effects of Agrobacterium co-cultivation stage on the induction of oxidative stress. This stress potentially causes lipid peroxidation, reduction of phytochemicals and chlorophyll pigments on explant tissue targeted for genetic transformation. This study, used double cotyledonary node explants infected and co-cultured with A. tumefaciens to evaluate total phenolics, antioxidant activity, lipid peroxidation and oxidative stress-induced tissue senescence during the cocultivation stage. The results, showed that, explant co-cultivation with Agrobacterium for 2, 4 and 6 days caused reductions in the amounts of phenolic compounds, chlorophylls and antioxidant activity due to tissue senescence, high oxidative stress and malondialdehyde contents. Percentage phenolic content of all bacteria infected explants ranged between 10.3-10.6 compared to $20.9 \%$ in the control. Chlorophyll content of about $1.49-4.00 \mathrm{mg} / \mathrm{ml}$ and malondialdehyde content ranging between 1.0-5.7 $\mathrm{mM}^{-1} \mathrm{~g}^{-1}$ were also recorded. Overall, findings suggest that the infection of explants with $A$. tumefaciens can induce oxidative stress and tissue senescence depending on the period of co-cultivation. However, reduced oxidative stress and senescence of explant tissues may potentially improve soybean shoot regeneration and transformation efficiency.

\section{Introduction}

Genetic transformation has rapidly advanced in the last three decades, and it now entails a wide range of regeneration protocols that are intended to broadly enhance plant growth and productivity of valuable legume crops (1). However, advancements in the establishment of an efficient in vitro regeneration system for genetic improvement is dependent on the type of explants used. Cotyledonary node system of transformation with or without pre-existing meristems have been widely reported in the production of genetically improved crop varieties (13 ). About one-third of the world's edible oils and twothird of protein meals are derived from such genetically improved soybean varieties. Furthermore, the use of Agrobacterium tumefaciens as a vehicle for the genetic improvement of recalcitrant legume crops such as soybean has promised higher yields, better seed quality, affordable soy-based products and the potential to rapidly raise agricultural economic gains in developing countries (1). Nevertheless, problems caused during explant-Agrobacterium interactions, that includes contamination or bacterial overgrowth, explant browning and senescence, as well as oxidative stress still pose many challenges. These factors are additional to constraints such as inefficient regeneration, genotype specificity and the lack of reproducibility of already tested tissue culture-based genetic transformation protocols as reported $(2,3)$. Amongst the above mentioned constraining factors, oxidative stress cause imbalances in the productions of reactive oxygen species (ROS) and antioxidants, leading to intense damage on plant cellular structures. ROS affect plant cells by altering plant's physiological and defense response mechanisms (4). ROS have unpaired electrons that form highly reactive, unstable free radicals, that when present in excess become harmful to cells and cause damage to cellular structures, including photosynthetic apparatus (4). The damage on cellular structures is hypothesised in this study, to cause negative effects on explant's proliferative capacity, causing tissue senescence and reduced developmental rate of tissues predetermined for de novo shoot organogenesis or subsequent production of transgenic plantlets. This study was

(C) Mangena (2021). This is an open-access article distributed under the terms of the Creative Commons Attribution License, which permits unrestricted use, distribution and reproduction in any medium, provided the original author and source are credited (https://creativecommons.org/licenses/by/4.0/) 
therefore, aimed at uncovering the effects of $A$. tumefaciens on cell proliferative capacity in cotyledonary explants through the evaluation of tissue senescence and oxidative stress following explant infection and co-cultivation with this bacterium. This study further hypothesised that ROS generated during the co-cultivation of soybean explants with Agrobacterium may exacerbate these negative physiological effects. Explant tissue senescence observed as a result of Agrobacterium infection was reported as a serious problem because it causes cell death in tissue culture, lowers shoot regeneration rates and negatively impact on soybean transformation frequency (5). Further insights on the cause and mechanism of this phenomenon in plant tissue culture and genetic transformation of plants would potentially assist in the optimisation of processes involved during genetic transformation in soybean and other valuable grain or forage crops.

\section{Materials and Methods}

The experiment was conducted at the Department of Biodiversity (P-Block building), at the University of Limpopo, Turfloop campus, South Africa, between September 2019 and May 2020. Mature seeds of cultivar LS677 used in this study were obtained from the Department of Plant Production, Soil Science and Agricultural Engineering at this University. The soybean (Glycine max (L.) Merr.) seeds were replanted at Amaloba Nursery at the same institution to obtain freshly harvested seeds, and this took place in the months of January to April 2019.

\section{Bacterial culture}

Agrobacterium tumefaciens strain EHA101 containing a pTF101.1 binary vector transformed with Oryza cystatin-1 gene (Oc-1) and phosphinothricin acetyl transferase bar gene for herbicide resistance was used in this study. Bacterial culture was obtained from the Forestry and Agricultural Biotechnology Institute (FABI) at the University of Pretoria in Tshwane, South Africa. The culture was reinitiated from a glycerol stock maintained in a freezer at $-80{ }^{\circ} \mathrm{C}$ and was allowed to grow to saturation in a liquid yeast extract peptone (YEP) medium supplemented with $50 \mathrm{mg} / \mathrm{l}$ kanamycin and $100 \mathrm{mg} / \mathrm{l}$ spectinomycin selectable markers (Rochelle Chemicals, Johannesburg, South Africa). The culture was incubated overnight on a shaker incubator (175 rpm) at room temperature and pelleted by centrifugation at $3500 \mathrm{~g}\left(28^{\circ} \mathrm{C}\right)$ for $10 \mathrm{~min}$. Agrobacterium suspension culture was then prepared by resuspending the pellet in a liquid infection medium and adjusted to 0.8 optical density $\left(\mathrm{OD}_{620}\right)$ before explant infection (6).

\section{Seed germination, explant preparation and co- cultivation with Agrobacterium}

Seeds of soybean (Glycine max (L.) Merr.), cultivar LS677 were decontaminated through surface sterilisation using chlorine gas before germination. Petri dishes with seeds were placed inside a desiccator jar alongside a $150 \mathrm{ml}$ beaker containing $100 \mathrm{ml}$ sodium hypochlorite (domestic bleach). Hydrochloric acid (3.5 ml) (Rochelle Chemicals, Johannesburg, South
Africa) was pipetted into the bleach to generate chlorine gas which was used to decontaminate the seeds for 16 hrs. Disinfected seeds were cultured for germination on Murashige and Skoog basal culture medium (7), supplemented with $1.76 \quad \mathrm{mg} / \mathrm{l}$ benzyladenine (BA) (Prestige Laboratory Suppliers, Johannesburg, South Africa). Seed cultures were incubated in a plant tissue culture growth room for 710 days at $24 \pm 2{ }^{\circ} \mathrm{C}$ temperature, $16 \mathrm{hr}$ photoperiod and 50-60 $\mathrm{mmolm}^{-2} \mathrm{~s}^{-1}$. Cotyledonary explants were prepared by excising-off the epicotyls and hypocotyls $5 \mathrm{~mm}$ beneath the cotyledons from the developed seedlings. Prepared explants were immersed in Agrobacterium suspension and incubated for $30 \mathrm{~min}$ on an orbital shaker at $174 \mathrm{rpm}$ at room temperature. Bacterial suspension was prepared by mixing Agrobacterium in a liquid Gamborg's B5 medium (infection medium) prepared as per standard procedure (6). Cotyledonary node explants used as a control were also incubated in the B5 medium without the bacterium. After incubation, the infected cotyledonary explants were co-cultured in petri dishes containing co-cultivation medium prepared (6) for 2,4 and 6 days in a growth room under conditions similar to those used for seed germination. Cotyledonary node explants used as a control were similarly incubated using an infection medium without Agrobacterium. The co-cultivated explants were then pulverised in liquid nitrogen, transferred into $50 \mathrm{ml}$ centrifuged tubes and kept at $-80^{\circ} \mathrm{C}$ until use.

\section{Total phenolics and antioxidant activity}

Total phenolics in co-cultivated cotyledonary explants were determined as gallic acid equivalents (8). A $1.0 \mathrm{~g}$ of pulverised explants was mixed with $10 \mathrm{ml}$ methanol, vortexed and centrifuged at $3500 \mathrm{~g}\left(28^{\circ} \mathrm{C}\right)$ for $10 \mathrm{~min}$. The extract was then mixed with FolinCiocalteau reagent (Rochelle Chemicals, Johannesburg, South Africa) and $1.5 \mathrm{ml}$ of $20 \%$ sodium carbonate $\left(\mathrm{Na}_{2} \mathrm{CO}_{3}\right) \quad$ (Prestige Laboratory Suppliers, Johannesburg, South Africa). The mixture was vortexed, incubated at room temperature for $10 \mathrm{~min}$, and the absorbance read at $765 \mathrm{~nm}$. Total phenolic content was then determined as GAE equivalent using the equation below, where $C$ is the concentration of gallic acid $(\mu \mathrm{g} / \mathrm{ml}), V$ volume of extract in $\mathrm{ml}$ and $M$ is the weight of extract (9).

\section{Equation (1):}

$$
\text { Total phenolics }=C \times \frac{V}{M}
$$

Antioxidant activity of the cotyledonary explants was determined using 1,1-Diphenyl-2-picrylhydrazyl (DPPH) assay as described (10). The reaction of DPPH with ascorbic acid and plant extracts were started by adding $1 \mathrm{ml}$ of $200 \mu \mathrm{M}$ DPPH solution (Rochelle Chemicals, Johannesburg, South Africa) in a series of dilutions, and the spectrophotometric measurements were done at 517 nm using a Jenway 7300/7305 spectrophotometer (Labotec, Johannesburg, South Africa). Equation 2 below was used to estimate the inhibitory percentage of DPPH where $A_{c}$ is the initial absorbance of stable DPPH radical without cotyledonary extracts and $A_{s}$ is the absorbance of 
$\mathrm{DPPH}$ radical in presence of sample (11). DPPH radical scavenging activity of extract was expressed as IC50 value and compared with ascorbic acid.

\section{Equation (2):}

$\%$ DPPH scavenging $=\left[\frac{\left(A c_{517 n m}-A s_{517 n m}\right)}{A c_{517 n m}}\right] \times 100$

\section{Chlorophyll content and lipid peroxidation}

Chlorophyll content was extracted and measured as described as per standard procedure (12). A $0.2 \mathrm{~g}$ of the homogenised cotyledonary explants was mixed with $15 \mathrm{ml}$ of $100 \%$ acetone, vortexed and incubated for $1 \mathrm{hr}$ in a BIOBASE thermostatic shaking water bath $\left(60{ }^{\circ} \mathrm{C}, 100 \mathrm{rpm}\right)$ (Lasec, Cape Town, South Africa). A cone of filter paper was inserted into a clean test tube and the homogenate poured through the filter paper to obtain acetone extract. Acetone extract was then measured using different wavelengths at 661.6, 664.8 and $661.6 \mathrm{~nm}$ to determine the total chlorophyll $\left(\mathrm{Chl}_{a+b}\right)$, chlorophylla $\left(\mathrm{Chl}_{a}\right)$ and chlorophyll-b $\left(\mathrm{Chl}_{b}\right)$ using the equations below (12).

Equation (3):

$$
\mathrm{Chl}_{a}=11.24 A_{661.6}-2.04 A_{644.8}
$$

\section{Equation (4):}

$$
\mathrm{Chl}_{b}=20.13 A_{644.8}-4.19 A_{661.6}
$$

\section{Equation (5):}

$$
C h l_{a+b}=7.05 A_{661.6}+18.09 A_{644.8}
$$

Malondialdehyde (MDA) content was determined by the reaction of 2-thiobarbituric acid (TBA) as described (13). A total of $0.4 \mathrm{~g}$ of homogenised cotyledonary nodes were mixed with $2 \mathrm{~mL}$ of $0.1 \%$ trichloroacetic acid (TCA) and centrifuged at $14000 \mathrm{~g}$ $\left(28{ }^{\circ} \mathrm{C}\right)$ for $15 \mathrm{~min}$. After centrifugation, $1 \mathrm{ml}$ of the supernatant was mixed with $2.5 \mathrm{ml}$ of $0.5 \%$ TBA in $20 \%$ TCA (Rochelle Chemicals, Johannesburg, South Africa) and incubated for $30 \mathrm{~min}$ in boiling water. The mixture was cooled in an ice bath immediately after incubation and absorbance read at 532/600 nm $\left(\mathrm{A}_{532} / \mathrm{A}_{600}\right)$. The concentration of MDA was determined using equation 5 below where $\mathrm{AC}$ refers to the absorbance coefficient, $156 \mathrm{mM}^{-1} \mathrm{~g}^{-1}$.

\section{Equation (6):}

$$
M D A=A_{532}-A_{600} \times 156 \mathrm{mM}^{-1} \mathrm{~cm}^{-1}
$$

\section{Visual analysis of tissue senescence}

The cotyledonary explants co-cultivated with Agrobacterium for 2, 4 and 6 days were visually analysed to evaluate the effect of this bacterium on tissue senescence. To validate the observed damaged features as true tissue damage, the co-cultivated cotyledonary nodes were assessed under a Leica EZ4 stereo microscope (Wetzler, Germany).

\section{Statistical analysis}

Data are mean \pm standard deviation, analysed using analysis of variance (ANOVA) with SPSS version 27 ( $P$ value <0.05). Means were separated using multifactorial test at the $5 \%$ level. The data was collected in triplicates and the study was repeated at least thrice, where data from the controls (2, 4 and 6 days incubation) was calculate as the total average of all respective observations made.

\section{Results}

\section{Determination of total phenolics and antioxidant activity}

As shown in Fig. 1 and Fig. 2, total phenolic contents and antioxidant activity were analysed on double cotyledonary node explants infected with Agrobacterium, and the control. Fig. 1 presents changes in total phenolic content assessed when cotyledonary explants were co-cultured with the

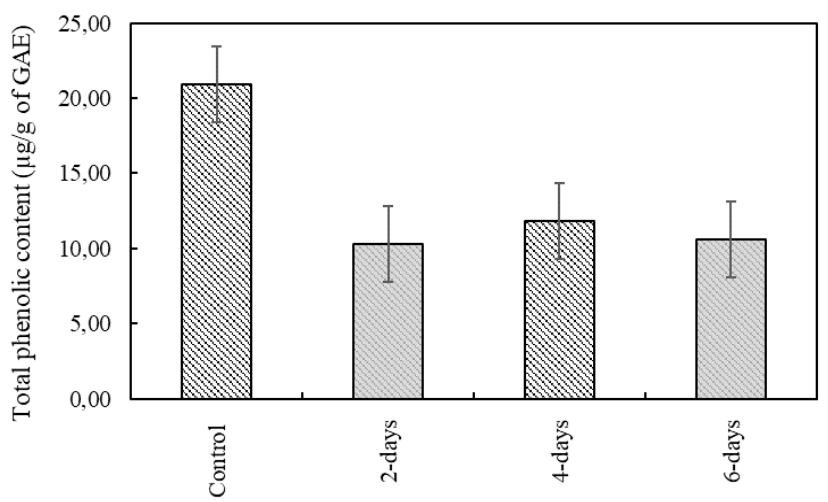

Fig. 1. A comparison of total phenolic content ( $\mu \mathrm{g}$ GAE/g dry weight) in cotyledonary explants used as control and explants co-cultured with Agrobacterium. Data represent mean content and the standard deviation (Std Dev).

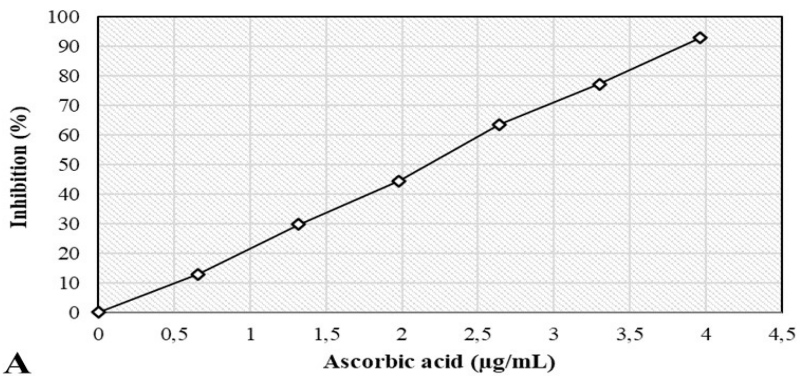

A

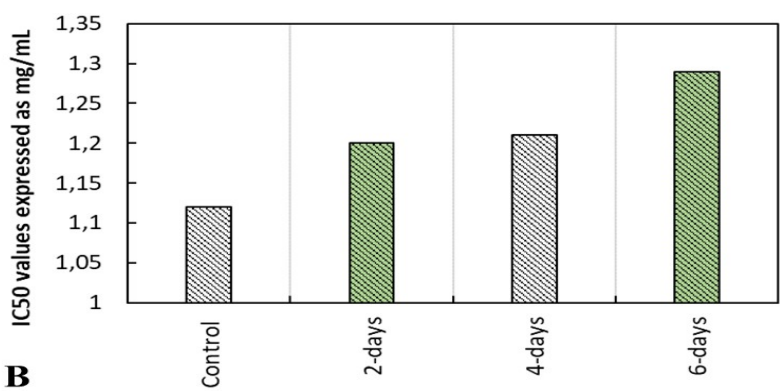

Fig. 2. DPPH radical scavenging activity by ascorbic acid (A) and values of IC50 by all cotyledonary node extracts infected with A. tumefaciens (pTF101.1) and the control without bacterial cocultivation (B). 
bacterium for 2-6 days and the control without bacterial infection/co-cultivation. According to the results, the highest total phenolic content of about $20.9 \%$ was recorded in the control, followed by explants co-cultivated for 4, 6 and 2 days of culture, respectively. An average decrease of $18 \%$ of total phenolic content was recorded in all infected explants compared to the control. Among the infected explants, cotyledonary nodes cultured for 4 days recorded the highest phenolic content of $11.8 \%$, followed by $10.6 \%$ for 6 days and $10.3 \%$ for 2 days of explant cocultivation with Agrobacterium. The results indicated that phenolic contents recorded were also significantly different, especially, among the Agrobacterium infected explants. This observation was illustrated by the decreasing tendencies of phenolic contents measured immediately after 2 days of co-cultivation, which showed an increase in 4 days cultured explants and then decreased again following explant-Agrobacterium interaction for 6 days. An equivalent average decrease in total phenolic content between explants co-cultured for $2(10.3 \%)$ and 6 (10.6\%) days were also observed as shown in Fig. 1. Generally, constantly high levels of phenolic content were obtained in the control, while a change in phenolic compound profile (with a drop ranging between 1.5-5\%) was observed in co-cultured explants upon infection and co-cultivation with the Agrobacterium.

As indicated above, co-cultivation of explants with Agrobacterium caused a significant decrease in the amounts of total phenolic content found in cotyledonary explants. According to the results, the recorded reductions in phenolic contents appeared to have negatively influenced the antioxidant activities of the infected cotyledonary explants. When free radical scavenging activity of the explants was measured and expressed as IC50 values in $\mathrm{mg} / \mathrm{ml}$, observations made showed that the extend of DPPH reaction in cotyledonary extracts was very low. According to Fig. 2, it appears that this trend was more predominant on soybean explants infected with Agrobacterium than in the extracts of cotyledonary node explants used as a control. The results also showed the strongest antioxidant scavenging activity when ascorbic acid was used as a standard (Fig. 2 A). However, all cotyledonary explants demonstrated different DPPH scavenging activity, which clearly reaffirmed that they all contained varied amounts of phenolic contents as indicated on Fig. 1 above. However, as expected, cotyledonary node explants used as a control exhibited the highest antioxidant activity which was characterised by the lowest IC50 value (Fig. 2 B). Results clearly showed that, this observation was in line with the high phenolic content recorded in the control as shown in Fig. 1. Further observations also indicated that, the highest antioxidant activity was observed in explants cocultured with Agrobacterium for 2 days, with the lowest IC50 value of $1.2 \mathrm{mg} / \mathrm{ml}$. A marginal but insignificant difference, however, was observed in cotyledonary explants co-cultivated for 4 days at 1.22 $\mathrm{mg} / \mathrm{ml}$, followed by the 6 day period of co-cultivation at $1.29 \mathrm{mg} / \mathrm{ml}$. The findings made clearly showed that, co-cultivated explants exhibited higher IC50 values compared to the control, demonstrating lower or very poor free radical scavenging activity due to explant infection with Agrobacterium. Lastly, according to the observations, antioxidant activities of cotyledonary explants were directly proportional to the period of co-cultivation as demonstrated in Fig. 2 (B). The IC50 values were increasing with the increase in the period of explant co-cultivation with Agrobacterium.

\section{Measurement of chlorophyll content}

Total chlorophyll content expressed as $\mathrm{mg} / \mathrm{ml}$ of all cotyledonary explants is presented in Fig. 3. According to these results, varied chlorophyll content profiles were observed in all Agrobacterium infected explants and control. Both co-cultivated explants (especially, explants co-cultivated for 2 days) and control showed

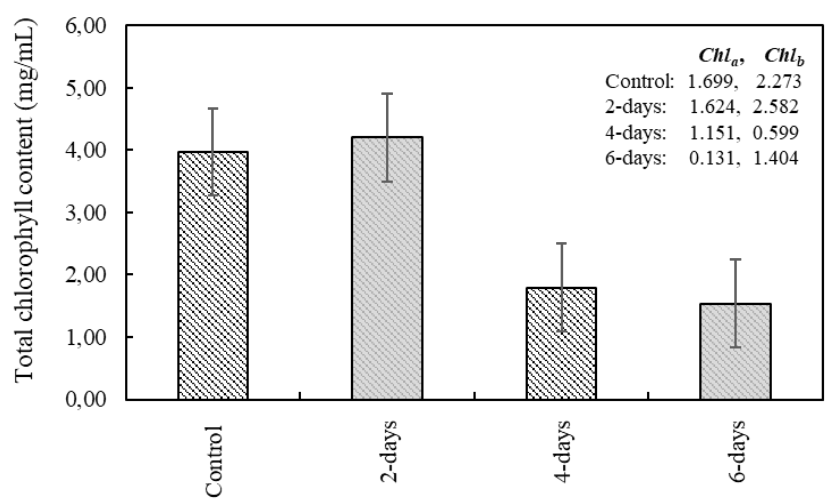

Fig. 3. A comparison of total chlorophyll content (mg/g dry weight) of cotyledonary node explants infected and co-cultured with Agrobacterium for 2, 4 and 6 days and explants used as a control.

increased amounts of chlorophyll contents of about 4.205 and $3.973 \mathrm{mg} / \mathrm{ml}$, respectively. Observations made also showed that, there were no significant differences found in chlorophyll amounts of cotyledonary explants co-cultivated for 2 days and the control as indicated in Fig. 3. Furthermore, overlapping error bars were observed in the control and 2 days co-cultivated explants, including the chlorophyll concentrations of explants co-cultivated with Agrobacterium for 4 and 6 days. According to the findings, there were also no significant differences found between the explants co-cultivated with Agrobacterium for 4 and 6 days. Meanwhile, significant variations were observed when there was a comparison between results of explants co-cultivated for 4 and 6 days, and those of control and explants cocultivated for 2 days. Generally, the results showed that, reductions in chlorophyll contents were observed during the co-cultivation period, and these chlorophyll amounts started to significantly decrease after 2 days of Agrobacterium infection and co-cultivation across the treatments.

\section{Evaluation of malondialdehyde content and tissue senescence}

According to the results on total phenolic content and antioxidant activity assay shown in Fig. 1 and 2, respectively, significant differences were observed between Agrobacterium co-cultivated and control explants. Similar to the phenolic content, DPPH assay and chlorophyll contents already reported above, Fig. 4 shows significant changes in the amounts of 
malondialdehyde contents recorded in all cotyledonary node explants. This organic molecule was generally increased in all double cotyledonary node explants infected with Agrobacterium for 2, 4

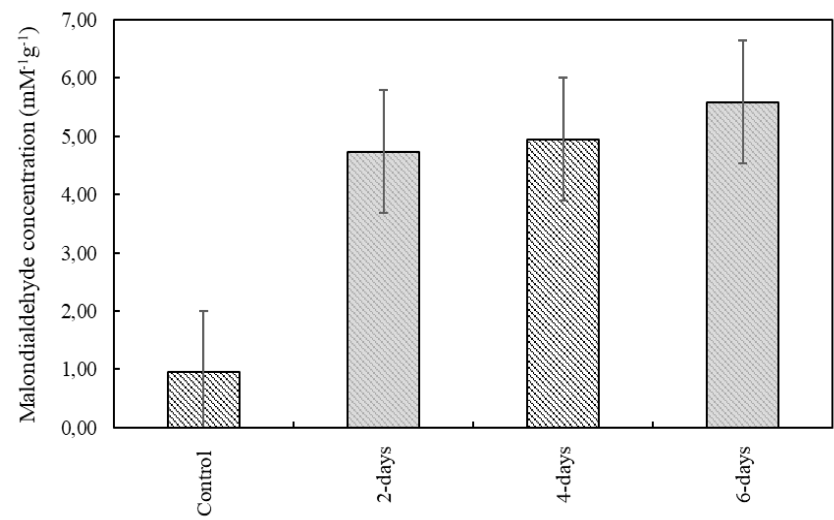

Fig. 4. Malondialdehyde concentrations $\left(\mathrm{mM}^{-1} \mathrm{~g}^{-1}\right)$ compared among co-cultivated cotyledonary explants infected with Agrobacterium for 2, 4 and 6 days and the uninfected control.

and 6 days at 4.5, 5.0 and $5.7 \mathrm{mM}^{-1} \mathrm{~g}^{-1}$, respectively. The observed findings suggests that there was potential oxidative stress that caused increases in the level of malondialdehyde contents. The amount of malondialdehyde is theoretically equivalent to lipid peroxidation and serves as a biochemical marker for lipid peroxidation. Thus, the results indicate that, the levels of lipid peroxidation were increasing with the increased duration of explants co-cultivation with Agrobacterium. However, the findings clearly showed that malondialdehyde contents were more elevated in explants co-cultivated for 6, 4 and 2 days, respectively. Furthermore, there was a slight variation of about 0.2 to $0.7 \mathrm{mM}^{-1} \mathrm{~g}^{-1}$ of malondialdehyde content among all Agrobacterium co-cultivated explants. These were particularly, observed between cotyledonary explants co-cultivated for 4 and 6 days of culture. However, it was also noted that malondialdehyde content increased by at least $4.89 \mathrm{mM}^{-1} \mathrm{~g}^{-1}$ in Agrobacterium infected explants compared to the control which recorded the lowest amount at $0.895 \mathrm{mM}^{-1} \mathrm{~g}^{-1}$ as illustrated in Fig. 4.

Tissue senescence in cotyledonary node explants was also visually inspected to evaluate the potential breakdown/ damage of tissue membranes in line with increased levels of malondialdehyde contents. According to the results, the extent of yellowing of explants and tissue browning/ blackening (senescence) indicated on Fig. 5 appeared to depend on the period of explant co-cultivation used. Tissue senescence was observed to be more pronounced on explants co-cultivated with Agrobacterium for 6, 4 and 2 days, respectively. It was, therefore, clearly observed that, prolonging explants co-cultivation with Agrobacterium, accelerated the development of deficiency symptoms. However, cotyledonary node explants used as a control did not presents any deficiencies or tissue senescence symptoms. Browning and subsequent darkening/ senescence of cocultivated explants negatively affected the proliferation of meristematic cells found at the cotyledonary junctions. As tissue senescence was more pronounced on explants co-cultured for 6 and 4

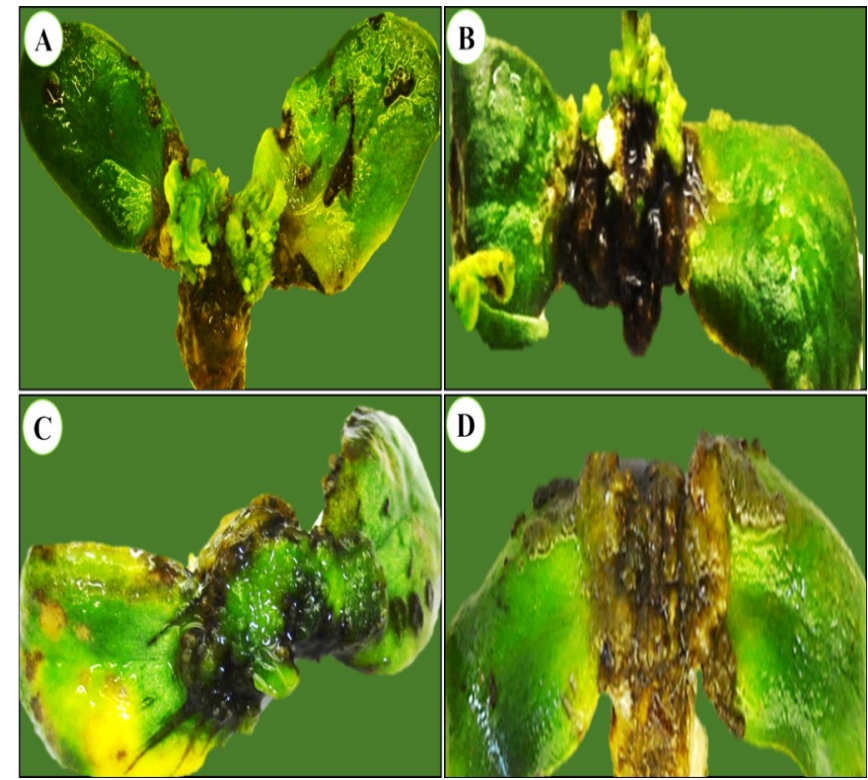

Fig. 5. Morphological response of cotyledonary explants used as control (A) and explants co-cultivated with Agrobacterium for 2 (B),

4 (C) and 6 (D) days. Tissue browning (D) caused the inhibition of buds/shoots initiation. Images were analysed at $8 \mathrm{X}$ resolution using a Leica EZ4 stereo microscope.

days, and only sectionally for 2 days co-cultivated explants as indicated in Figure 5. Consequently, very little or lack of shoot bud initiations were observed on explants infected with Agrobacterium (Fig. 5 B, C and D) compared to cotyledonary nodes used as a control (Fig. 5 A). Co-cultivation with Agrobacterium had more severe effects on explants incubated for 6 days which presented complete lack of cell proliferation neither into callus nor bud initiation. According to the results, there was no indication of tissue proliferation even for callus formation in response to injury/wounding during explant preparation or formation of buds from existing axillary meristems found on the cotyledonary junctions. These observations clearly indicated reduced free radical scavenging activity as a result of the decreased total phenolic content and increased amounts of malondialdehydes, and the effects were exacerbated by further reductions on chlorophyll contents recorded in all cotyledonary explants cocultivated with Agrobacterium.

\section{Discussion}

This study evaluated the levels of total phenolic content and antioxidant activity following explants cocultivation with Agrobacterium. As reported (11) phytochemicals such as phenolic compounds play an important role in plant defence mechanism and as singlet oxygen scavengers. As indicated by the results, the decrease in phenolic content of infected explants potentially caused a reduction in their capacity to prevent oxidative stress. Furthermore, this caused severe explant tissue senescence as a result of enhanced susceptibility of these tissues to bacterial overgrowth, and lack of effective scavenging activity during the co-cultivation of cotyledonary node explants with Agrobacterium, as supported by the study (14). The cited report indicated that longer cocultivation periods potentially increased the number 
of successful transformation events, while causing detrimental effects on the proliferative capacity of explants due to bacterial overgrowth. Agrobacteriummediated transformation is initiated by wounding of plant tissues, and the wounding lead to the release of phenolic compounds attracting the bacteria to target cells (15). However, the reduction of post infection phenolic acids production indicate the inability of explants to enhance transformation events and prevent oxidative stress in the targeted cells. This was further supported by the low antioxidant activity observed on infected explants, compared to the controls with a verification by its lower IC50 value recorded. It also indicated that a lower IC50 value reflects high antioxidant activity and high IC50 value is associated with low scavenging activity (16). The role of chlorophyll during photosynthesis is also vital, particularly throughout stress where the need for plants to convert carbon dioxide and water to oxygen and sugars is highly necessary. Of course, bearing in mind that, this process and life in general is solar powered. The radiant energy from the sun is then converted to chemical energy stored in sugars and other organic molecules. Although, chlorophylls are natural pigments that absorb light energy for photosynthesis (17), some of these pigments such as carotenoids play a critical role in protecting cells and tissues from free radicals, improving antioxidant activity. Furthermore, the energy absorbed by these pigments is used in synthesising phytochemicals through the central Shikimic acid and acetic acid pathways (18). The differences observed in chlorophyll content profile of the co-cultured cotyledonary explants serves as an indicator of explant vigour and capacity to photosynthesise, especially to provide energy for the proliferative tissues. An increase or consistency in the level of chlorophyll content before and after infection could improve the in vitro regeneration of induced shoots and perhaps subsequent efficient recovery of transgenic microshoots from infected cotyledonary explants. Findings made in this study and in the literature support the notion that a direct relationship exist between total chlorophyll content and oxidative stress caused by environmental cues. This is in addition to $A$. tumefaciens induced explant damage or oxidative stress as also alluded $(17,19,20)$. Changes in membrane structure of the infected cells and morphology of explants analysed through visual inspection post Agrobacterium infection also revealed differences among the treatments. These variations were discussed in detail in some of our previous studies $(1,3,20)$. The results also indicated an increase in malondialdehyde concentration after co-cultivation. This new evidence suggests a strong association of this transformation stage to potential lipid peroxidation that may be taking place on infected explants. Thus, Agrobacterium co-cultivated explants generally showed higher levels of malondialdehyde probably as a result of oxidative stress caused by bacterial infection. According to one report, co-cultivation period influenced the level of abrasive effects of infection that was also influenced by the type of explant target tissues used (21). Consequently, bacterial cells appeared to have overwhelmed and lacerated cotyledonary explants at the meristematic tissue regions found on the cotyledonary junctions, which may be limiting to regeneration and transformation efficiencies. It was emphasised that, the generation of ROS can cause damage to the cellular and molecular structure of stressed plant tissues (13). However, the findings made in this study clearly showed that co-cultivation of explants with Agrobacterium exacerbated ROS effects and lipid peroxidation, and the infected explant failed to defend themselves due to lower amounts of phytochemicals and pigments produced.

\section{Conclusion}

Data obtained in this study suggested that total chlorophyll content, phenolic content and free radical scavenging activity of cotyledonary nodes were significantly reduced by explants co-cultivation with $A$. tumefaciens. Results confirm the negative influences of the co-cultivation stage through Agrobacterium-mediated genetic transformation on the quantity of phenolic compounds required for improved antioxidant activity. Overall, these findings imply that the infection of explants with $A$. tumefaciens cause oxidative stress and tissue senescence which may subsequently have an impact on genetic transformation in soybean, Glycine max (L.) Merr. Furthermore, this study discovered that Agrobacterium infection and co-cultivation of explants cause increased malondialdehyde content in the tissues, demonstrating enhanced lipid peroxidation during co-cultivation stage. The study provides additional information relating to the factors affecting Agrobacterium-mediated genetic transformation as previously reported (20).

\section{Acknowledgements}

This research was funded by the National Research Foundation [129747] of South Africa and The APC was funded by Department of Research Administration and Development of the University of Limpopo.

\section{Conflict of interests}

The author declares that there is no conflict of interest regarding the publication of this paper.

\section{References}

1. Mangena P. Genetic transformation to confer drought stress tolerance in Soybean (Glycine max L.). In: Guleria P, Kumar V, Lichtfouse E (eds) Sustainable Agriculture Reviews 45. Sustainable Agriculture Review. 2020; vol 45. Springer, Cham. https:// doi.org/10.1007/978-3-030-53017-4_10

2. Li S, Y Cong, Y Liu, T Wang, Q Shuai, N Chen, J Gai J, Y Li. Optimization of Agrobacterium-mediated transformation in soybean. Front Plant Sci. 2017;8(246):1-15. https://doi.org/10.3389/ fpls.2017.00246

3. Mangena P, EKM Sehaole. Transgenic grain legumes. In: Mangena P (eds) Advances in Legume Research- Physiological Responses and Genetic Improvement for Stress Resistance. Bentham Science Publishers, Singapore. 2020; vol 1, pp. 148-72. https://doi.org/10.2174/9789811479625120010011

4. Hsieh C, S Fernandez-Tome, B Hernandez-Ledesma. Functionality of soybean compounds in the oxidative stress-related dis- 
orders. In: Gracia-Sancho J, Salvado J (eds) Gastrointestinal Tissue: Oxidative Stress and Dietary Antioxidant. Academic Press. 2017; pp. 339-53. https://doi.org/10.1016/B978-0-12-8053775.00027-8

5. Dan Y. Biological functions of antioxidants in plant transformation. In Vitro Cell Dev Biol Plant. 2008;44(3):149-61. https:// doi.org/10.1007/s11627-008-9110-9

6. Paz MM, JC Martinez, AB Kalvig, TM Fonger, K Wang. Improved cotyledonary node method using an alternative explant derived from mature seed or efficient Agrobacterium-mediated soybean transformation. Plant Cell Rep. 2006;25:206-13. https://doi.org/ 10.1007/s00299-005-0048-7

7. Trigiano RN, DJ Gray. Plant development and biotechnology. CRC Press, Washington, D.C., 2005; pp. 9-37.

8. Baskaran P, M Moyo, J van Staden. In vitro plant regeneration, phenolic compound production and pharmacological activities of Coleonema pulchellum. S Afr J Bot. 2014;90:74-79. https:// doi.org/10.1016/j.sajb.2013.10.005

9. Nikolova M, M Petrova, E Zayoza, A Vitkova, L Evstatieva. Comparative study of in vitro, ex vitro and in vivo grown plants of Arnica montana-polyphenols and free radical scavenging activity. Acta Bot Croat. 2013;72(1):13-22. https://doi.org/10.2478/ v10184-012-00139

10. Sharma OP, TK Bhat. DPPH antioxidant assay revisited. Food Chem 2009;113:1202-05. https://doi.org/10.1016/j.foodchem.2008.08.008

11. Jimoh MO, AJ Afolayan, FB Lewu. Antioxidant and phytochemical activities of Amaranthus caudatus L. harvested from different soils at various growth stages. Sci Rep. 2019;9: 12965. https://doi.org/10.1038/s41598-019-49276

12. Boyer RF. Isolation and spectrophotometric characterization of photosynthetic pigments. Biochem Edu. 1990;18(4):203-06.

13. Ali MB, EJ Hahn, KY Paek. Effects of light intensities on antioxidant enzymes and malondialdehyde content during short-term acclimatization on micropropagated Phalaenopsis plantlet. Environ Exp Bot. 2005;54:109-20. https://doi.org/10.1016/j.envexpbot.2004.06.005

14. Zhang Z, JJ Finer. Low Agrobacterium tumefaciens inoculum levels and a long co-culture period lead to reduced plant defense responses and increase transgenic shoot production of sunflower (Helianthus annuus L.). In Vitro Cell and Dev BiolPlant. 2016;52:354-66. https://doi.org/10.1007/s11627-016-9774-5

15. Zia M, W Arshad, Y Bibi, S Nisa, MF Chaudhary. Does Agro-injection to soybean pods transform embryos? Plant Omics J. 2011;4(7):384-90. https://pomics.com/zia_4_7_2011_384_390.pdf
16. Jain R, SK Jain. Total phenolic contents and antioxidant activities of some selected anti-cancer medicinal plants from Chhattisgarh State, India. Pharmacologyonline. 2011;2:755-62.

17. Golkar P, A Arzani, AM Rezaei, Z Yarali, M Yousefi. Genetic variation of leaf antioxidants and chlorophyll content in safflower. Afr J Agric Res. 2010;4(12):1475-82.

18. Adams ZP, J Ehlting, R Edwards. The regulatory role of shikimate in plant phenylalanine metabolism. J Theor Biol. 2019;462:158-570. https://doi.org/10.1016/j.jtbi.2018.11.005

19. Choi DG, NH Yoo, CYY Yu, BL Reyes, SJ Yun. The activities of antioxidant enzymes in response to oxidative stresses and hormones in paraquat-tolerant Rehmannia glutinosa plants. J Biochem Mol Biol. 2004;37(5):618-24. https://www.doi.org/ 10.5483/bmbrep.2004.37.5.618

20. Paz MM, JC Martinez, AB Kalvig, TM Fonger, K Wang. Assessment of conditions affecting Agrobacterium-mediated soybean transformation using the cotyledonary node explant. Euphytica. 2004;136:167-79. B:EUPH.0000030669.75809.dc

https://doi.org/10.1023/

21. Hiei Y, S Ohta, T Komari, T Kumashiro. Efficient transformation of rice (Oryza sativa L.) mediated by Agrobacterium and sequence analysis of the boundaries of the T-DNA. Plant J. 1994;6:271-82.

Additional information

Peer review information: Plant Science Today thanks Sectional Editor and the other anonymous reviewers for their contribution to the peer review of this work.

Reprints and permissions information is available at https://horizonepublishing. com/journals/index.php/PST/open_access_policy

Publisher's Note: Horizon e-Publishing Group remains neutral with regard to jurisdictional claims in published maps and institutional affiliations.

To cite this article: Mangena P. Effect of Agrobacterium co-cultivation stage on explant response for subsequent genetic transformation in Soybean (Glycine max L. Merrill.). Plant Science Today. 2021;8(4):905-911. https://doi.org/10.14719/ pst.2021.8.4.1363

Plant Science Today, published by Horizon e-Publishing Group, is covered by Scopus, Web of Science, BIOSIS Previews, Clarivate Analytics, etc. See https://horizonepublishing.com/journals/index.php/PST/indexing_abstracting 